ZOOLOGIA 31 (4): 316-322, August, 2014

http://dx.doi.org/10.1590/S1984-46702014000400002

\title{
Locomotion and survival of two sympatric larval anurans, Bufo gargarizans (Anura: Bufonidae) and Rana zhenhaiensis (Anura: Ranidae), after partial tail loss
}

\author{
Guo-Hua Ding ${ }^{1}$, Zhi-Hua Lin ${ }^{1,2} \&$ Li-Hua Zhao
}

\author{
${ }^{1}$ College of Ecology, Lishui University, Lishui, Zhejiang 323000, China. \\ 2 Corresponding author. E-mail: zhlin1015@126.com
}

\begin{abstract}
Tadpoles of two sympatric anurans, Bufo gargarizans Cantor, 1842 and Rana zhenhaiensis Ye, Fei \& Matsui, 1995, were used as model organisms to examine the effects of different levels of tail loss on swimming performance and survival. On average, B. gargarizans tadpoles were shorter and had smaller tails and body mass than $R$. zhenhaiensis. After $75 \%$ tail loss, the survival rate of experimental and control B. gargarizans tadpoles, and of experimental tadpoles of the two species, differed significantly; the number of tadpoles surviving a complete impairment of their swimming ability did not differ between B. gargarizans and R. zhenhaiensis. After 50\% tail loss, the swimming performance (swimming speed, maximum distance and number of stops) of the two species was significantly affected. However, the adverse influence of tail loss on the swimming speed of $B$. gargarizans tadpoles was greater compared to $R$. zhenhaiensis tadpoles. Our data indicates that a $50 \%$ tail loss results in swimming costs for B. gargarizans and $R$. zhenhaiensis tadpoles, and that $75 \%$ tail loss decreases the survival rate of $B$. gargarizans tadpoles. Therefore, we conclude that tadpoles of different species and with the same degree of tail loss use distinctive strategies to improve individual fitness in the face of predator pressure.
\end{abstract}

KEY WORDS. Survival rate; swimming performance; sympatric species; tadpole; tail removal.

The tail of anuran tadpoles is viscoelastic and fragile. When a larva is grasped by an aquatic predator, its tail will stretch and then tear apart (Morin 1985, DoherTy et al. 1998). A high level of tail damage was found by BLAIR \& WASSERSUG (2000) in a wild population of tadpoles. Tail damage in tadpoles can be caused by vertebrates, such as fish, turtles and salamanders, and by invertebrates, such as crayfish and dragonfly larvae (Wilbur \& Collins 1973, Caldwell et al. 1980, Van Buskirk \& McCollum 2000a, Van Buskirk et al. 2003, Wilson et al. 2005).

According to some studies, larger tails not only improve the swimming performance of tadpoles, but they also help tadpoles to escape from aquatic predators by allowing them to turn suddenly and burst their speed (SMITH \& VAN BUSKIRK 1995, Van Buskirk \& McCollum 2000b, Teplitsky et al. 2005, Arendt 2010). However, other studies have shown that tadpoles usually do not have a chance to generate defensive responses (Zоттоц et al. 2001) or increase their swimming speed before being attacked by an aquatic predator (VAN BUSKIRK \& MCCOLLUM 2000a, LUQUET et al. 2011). Experimental manipulations of tadpoles with tail damage have revealed that swimming performance is affected only after large tail segments are removed (Hoff \& Wassersug 2000, Van Buskirk \& McCollum 2000b).

Some researchers have suggested that the tail of tadpoles, amphibians and other animals may function as a lure for predators, (CAldwell 1982, Hoff \& Wassersug 2000, Miner et al. 2005,
LAURILA et al. 2008, Lu et al. 2012). The relatively longer tail of tadpoles may distract predators from more vulnerable areas of the prey's body, such as head and thorax (KisHida et al. 2010). Considering that predators use visual stimuli to hunt and that the tails of tadpoles have vivid colors, this luring mechanism might increase the probability that a tadpole will survive an attack (Caldwell 1982, McCollum \& Van Buskirk 1996, Skelly 1997, VAN BusKirk et al. 2003).

A high frequency of tail damage has been observed in natural populations of tadpoles, which indicates that $B$. gargarizans tadpoles can only escape from an aquatic predator if their tail is grabbed first (Blair \& Wassersug 2000, Doherty et al. 1998). However, it remains to be investigated whether mortality risk is really lower when the tadpole is attacked by the tail, and also whether a larger tail works against the prey by calling the attention of aquatic predators (VAN BuskIRK et al. 2003).

Circumstantial evidence has revealed that, even though tadpoles with substantial tail damage are able survive, their survival rate is lower when compared with their intact counterparts (Blair \& WASSERSUg 2000, Johnson et al. 2008). In fact, the swimming speed and maximum distance traveled by Hyla chrysoscelist tadpoles were significantly affected when more than 50\% of their tail was cut off (Figiel \& SemLitsch 1991).

Bufo gargarizans Cantor, 1842 and Rana zhenhaiensis Ye, Fei \& Matsui, 1995 are two sympatric anuran amphibians in 
Lishui, East China, which share the same breeding season, from December to March (Fer et al. 2009). Tail damage can be commonly observed in tadpoles of the two species, and tadpoles with serious tail loss are often found dead in natural ponds (FeI et al. 2009). In our study, we address two questions: 1) Does the swimming speed of $B$. gargarizans and $R$. zhenhaiensis tadpoles differ when the length of their tails differs, thus providing evidence that tail length is important for swimming speed in tadpoles? 2) Do different levels of artificial tail loss (50\%, $75 \%$ ) result in negative effects on swimming performance and survival rate in both $B$. gargarizans and $R$. zhenhaiensis tadpoles?

\section{MATERIAL AND METHODS}

Our experimental procedures complied with the current laws on animal welfare and research in China, and were specifically approved by the Animal Research Ethics Committee of Lishui University (Permit number AREC-LU 2011-03).

The tadpole of $B$. gargarizans is a toad tadpole with entirely black body, while the tadpole of $R$. zhenhaiensis is a frog tadpole with grey body and transparent abdomen (Fei et al. 2009). Both larval anurans share the same habitat in Lishui from January to April of every year (Fei et al. 2009). Tadpoles of both species were collected in early April, 2011, from natural ponds in Lishui $\left(28^{\circ} 27^{\prime} \mathrm{N}, 119^{\circ} 54^{\prime} \mathrm{E}\right.$, altitude $\left.200 \mathrm{~m}\right)$, Zhejiang province, China. All individuals captured were transported to the Herpetological Laboratory of the Lishui University (HLLSU), where they were identified. Vouchers of $B$. gargarizans tadpoles were deposited as HLLSU-2011041034, HLLSU-2011041040, HLLSU-2011041046, HLLSU-2011041052, HLLSU-2011041055, HLLSU-2011041067, HLLSU-2011041074, HLLSU-2011041081, HLLSU-2011041086, HLLSU-2011041093. Rana zhenhaiensis tadpoles were deposited as HLLSU-2011041303, HLLSU2011041310, HHLLSU-2011041317, HLLSU-2011041326, HLLSU-2011041331, HLLSU-2011041337, HLLSU-2011041338, HLLSU-2011041355, HLLSU-2011041356, HLLSU-2011041361.

Tadpoles were reared in $60 \times 40 \times 40 \mathrm{~cm}$ (length $\times$ width $\times$ height) plastic tubes with $50 \mathrm{~L}$ aged tap water, respectively. Spirogyra and egg yolk were provided, and the water in each plastic tube was replaced every day. Plastic tubes were placed in a room, and water temperature was kept at $20 \pm 0.5^{\circ} \mathrm{C}$. The developmental stages of tadpoles of both anurans were determined between G30 and G34, following the criteria of GosNer (1960).

Bufo gargarizans $(\mathrm{n}=39)$ and $R$. zhenhaiensis $(\mathrm{n}=40)$ tadpoles without tail injury were randomly assigned to experimental (hereafter E tadpoles) and control groups (hereafter $\mathrm{C}$ tadpoles), respectively. The number of $\mathrm{E}$ tadpoles and $\mathrm{C}$ tadpoles were 19 and 20 for $B$. gargarizans, 20 and 20 for $R$. zhenhaiensis, respectively. To avoid the interference of food intake on swimming performance, no food was given to tadpoles 24 hours before the experiment. Each tadpole was individually placed in a $10 \times 5 \times 5 \mathrm{~cm}$ (length $\times$ width $\times$ height) plastic bin containing $150 \mathrm{ml}$ aged tap water, which was kept at $20 \pm$ $0.5^{\circ} \mathrm{C}$, for 2 hours. The swimming performance of tadpoles in 80 -cm-long straight line (water temperature was set at $20^{\circ} \mathrm{C}$ ) was recorded by a high-speed digital camera from the same angle relative to the direction of movement. Video files were examined with a computer using SiLICON software for swimming speed in the fastest $10 \mathrm{~cm}$ interval, maximum distance traveled without stopping (hereafter maximum distance) and number of stops in the trail.

After obtaining data on the swimming performance of $\mathrm{E}$ and $\mathrm{C}$ tadpoles with intact tails (hereafter E0), tail segments were removed twice with a scalpel from E subjects at one-day intervals (tadpoles had one day to heal the wound after each tail-removing episode, to control for the direct influence of handling stress), thereby producing tadpoles with 50\% tail loss (hereafter E1) and 75\% tail loss (hereafter E2), respectively. The swimming performance of all tadpoles was then calculated by following the procedures described above. Before the first tail loss treatment, each tadpole was weighed and its tail was measured using a digital vernier caliper. The swimming performance of $\mathrm{C}$ tadpoles was also also measured to serve as control for the two subsequent measurements taken from $\mathrm{E}$ tadpoles. If a subject covered a swimming distance of less than $1 \mathrm{~cm}$ in 1 minute, the tadpole was considered lacking in swimming ability.

Prior to parametric analyses, data were tested for normality by the Kolmogorov-Smirnov test, and for homogeneity of variances by the Bartlett's test. No data needed to be transformed to achieve the conditions for using parametric analyses. We used log-likelihood ratio test (G-test) to examine whether the survival rate differed between the $\mathrm{E}$ and $\mathrm{C}$ tadpoles after $75 \%$ tail loss in two species, and whether the number of individuals for which swimming performance could be determined differed between the experimental B. gargarizans and $R$. zhenhaiensis tadpoles after $75 \%$ tail loss. We used two-way ANOVA to analyze developmental stage and body length, two-way ANCOVA for the analysis of tail length and body mass with body length as covariate, and repeated-measures ANOVA to assess differences in the number of stops, maximum distance and swimming speed. Tukey's post hoc comparison was performed to assess differences among the results. All statistical analyses were performed with the Statistica software (version 6.0 for PC, Tulsa, OK, USA). Descriptive statistics values were presented as mean \pm standard error (SE), and the significance level was set at $\alpha=0.05$.

\section{RESULTS}

Before the treatment, we compared the differences in developmental stage and morphology between $B$. gargarizans and $R$. zhenhaiensis tadpoles. The mean value for developmental stage did not differ between the $\mathrm{E}$ and $\mathrm{C}$ tadpoles, nor between the two species; the mean value for body length in $B$. gargarizans tadpoles was significantly smaller than in $R$. zhenhaiensis tadpoles; the mean values for tail length and body mass were significantly smaller in $B$. gargarizans tadpoles than 
in $R$. zhenhaiensis tadpoles after accounting for body length; the interaction between animal category (E vs. C tadpoles) and species was not a significant source of variation in developmental stage, body length and tail length, but affected the body mass significantly (Table I).

After 50\% tail loss, no tadpoles died. After 75\% tail loss, the survival rate of $B$. gargarizans differed between $E(13 / 19)$ and C $(20 / 20)$ tadpoles (G-test, $G=9.79, \mathrm{df}=1, \mathrm{p}<0.002)$. By contrast, the survival rate of $\mathrm{E}$ and $\mathrm{C}$ tadpoles did not differ for R. zhenhaiensis (Fig. 1). Between E subjects of both species, the survival rate showed significant differences (G-test, $G=9.79$, $\mathrm{df}=1, \mathrm{p}<0.002$ ) (Fig. 1). After 75\% tail loss, the number of surviving tadpoles that lacked swimming ability did not differ between $B$. gargarizans $(0 / 13)$ and $R$. zhenhaiensis tadpoles (3/ 20) (G-test, $\mathrm{G}=3.20$, df $=1, \mathrm{p}=0.074$ ) (Fig. 2). Swimming performance after $75 \%$ tail loss could not be measured for most E subjects of both species, therefore this data were not considered in the analysis.

Given that the three swimming variables were independent from body length in each species (all p > 0.072), we used repeated-measured ANOVA to examine swimming performance in the two species after 50\% tail loss. Species and animal category (E vs. C tadpoles) were defined as between-subject factor and tail-removing order was defined as within-subject factor. The data showed that: 1) the mean swimming speed of $B$. gargarizans tadpoles was significantly lower than in $R$. zhenhaiensis tadpoles. However the mean number of stops and maximum distance were not significantly different for the two species. Precisely, 2) the mean number of stops of tadpoles in E0 was less than in E1, whereas the mean values for maximum
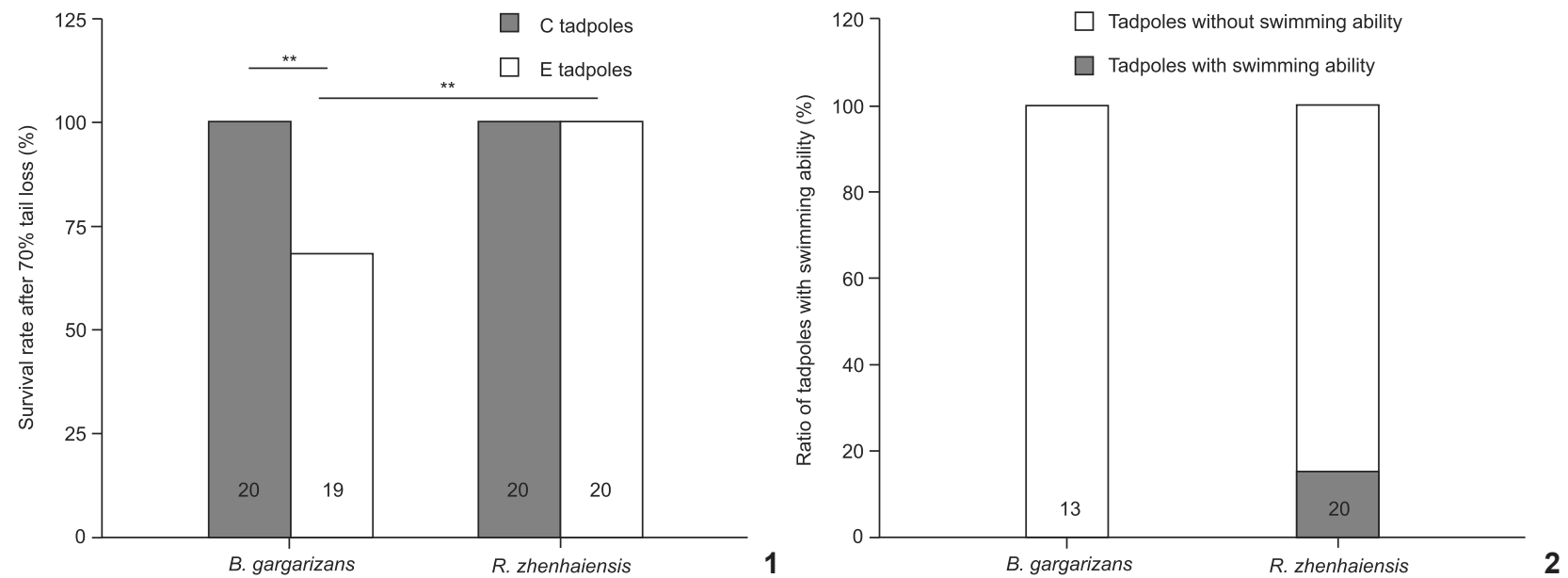

Figures $1-2$. The effect of $75 \%$ tail loss on survival rates (1) and swimming ability (2) in B. gargarizans and $R$. zhenhaiensis tadpoles. Sample sizes in the two species are showed in the figure. ${ }^{* *}: p<0.01$.

Table I. Descriptive statistics, expressed as mean \pm SE and range, for developmental stage and morphological traits (body length, tail length and body mass) of $B$. gargarizans and $R$. zhenhaiensis tadpoles used to examine the effect of tail loss on swimming performance and survival rate. F values of two-way ANOVA (for developmental stages and body length) and ANCOVA (for tail length and body mass with body length as the covariate).

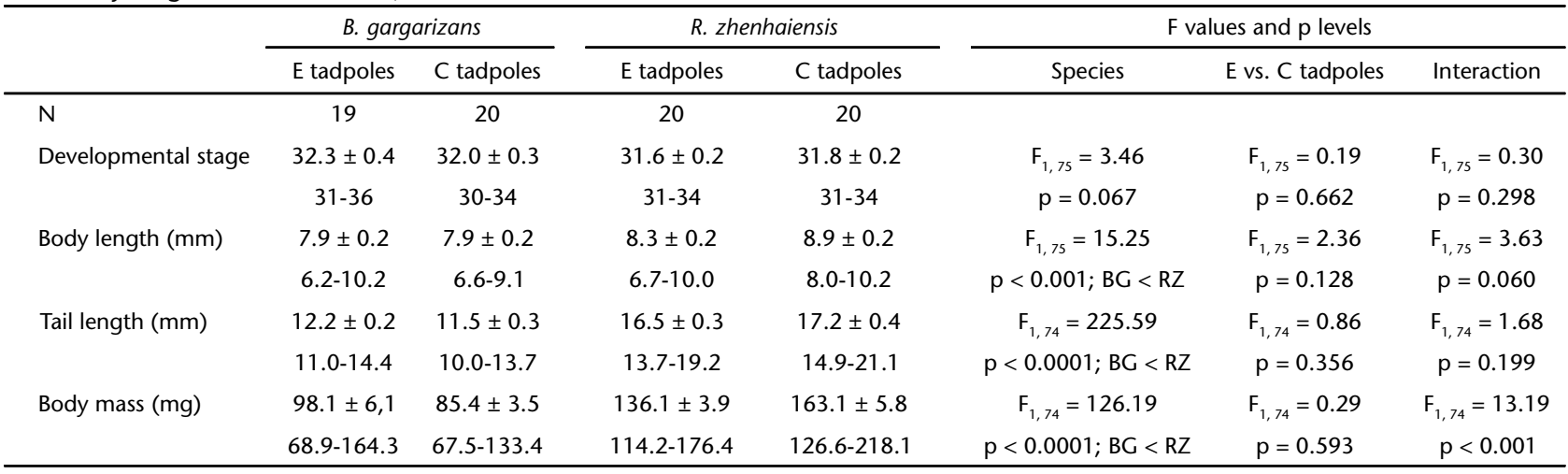

BG: B. gargarizans, RZ: R. zhenhaiensis; E tadpoles: Experimental tadpoles, C tadpoles: Control tadpoles. 
distance and swimming speed of tadpoles in E0 were greater than in E1. 3) The mean value for number of stops in the $\mathrm{C}$ tadpoles was less than in the $\mathrm{E}$ tadpoles, whereas the mean values for maximum distance and swimming speed were greater than in the E tadpoles (Table II, Fig. 3).

\section{DISCUSSION}

When intact, the tails of $B$. gargarizans and R. zhenhaiensis tadpoles differ significantly in length, which may be responsible for the differences in the swimming performance of both species. The fact that larger intact tails are associated with higher swimming speed had already been documented (VAN BuskiRK \& McCollum 2000b, Teplitsky et al. 2005, Arendt 2010). After accounting for body length, our results showed that intact tails of B. gargarizans tadpoles were significantly smaller than of $R$. zhenhaiensis tadpoles (Table I). Furthermore, before tail loss, the mean swimming speed of $B$. gargarizans tadpoles $(7.8 \mathrm{~cm} / \mathrm{s})$ was significantly slower than of $R$. zhenhaiensis tadpoles $(10.6 \mathrm{~cm} / \mathrm{s})$ (Fig. 3). Therefore, our results are consistent with the idea that larval anurans with relatively longer tails swim faster.

The results of our study showed that the effect of $50 \%$ tail loss on the swimming performance of B. gargarizans and $R$. zhenhaiensis was significant. This decreased performance was expressed in the following ways: increased number of stops (57\%), decreased maximum distance (27\%), and decreased swimming speed (51\%) (Fig. 3). The swimming speed in both species decreased after 50\% tail loss (Fig. 3), showing that the tail plays a crucial role in this variable (VAN BuskiRK \& McCollum 2000b, MARvin 2011, 2013). Nevertheless, the reduced swimming speed of B. gargarizans tadpoles (51\%) was greater than of $R$. zhenhaiensis tadpoles (20\%) after 50\% tail loss, which indicates that cost was relatively lower for $R$. zhenhaiensis tadpoles than for B. gargarizans when both species suffered the same level of tail damage. In our results, $75 \%$ tail loss reduced the swimming ability of our subjects so much that we were not able to measure their swimming performance. Kinematic data have demonstrated that, in tadpoles, swimming propulsion is not produced by the entire tail (WASSERSUG \& HOFF 1985), but predominantly by the distal part of it (Blair \& Wassersug 2000). Our results have shown that a high degree of tail loss (75\% or more) may not only significantly affect the swimming performance of tadpoles, but also their ability to forage and escape predators, reducing the survival rate of individuals (VAN BusKirK et al. 2003, MAGINNIs 2006) (Figs 1 and 2). After $75 \%$ tail loss, the survival rate of experimental B. gargarizans tadpoles (68.4\%) was significantly lower than of experimental R. zhenhaiensis tadpoles (100\%) (Fig. 1), which suggests that $B$.gargarizans tadpoles with serious tail damage are more prone to dying than $R$. zhenhaiensis tadpoles. Our results show that after $75 \%$ tail loss there were no differences in the swimming ability of the two species. However, $15 \%$ of $R$. zhenhaiensis tadpoles kept their swimming ability, contrasting with $0 \%$ of $B$. gargarizans tadpoles (Figs 1 and 2). This result may suggest that in natural ponds serious tail loss incurs in higher swimming cost for B. gargarizans tadpoles. In conclusion, it seems that the adaptive ability and viability of $B$. gargarizans tadpoles is lower than of $R$. zhenhaiensis tadpoles when tail loss is concerned.

In natural ponds, the proportion of $B$. gargarizans tadpoles with tail damage was two times lower than of $R$. zhenhaiensis tadpoles (L. Wei, unpub. data), which may be explained by the following: 1) The different niches of the two sympatric tadpoles may result in $R$. zhenhaiensis tadpoles being attacked more frequently than B. gargarizans. Aquatic predators are more widely distributed closer to the surface of ponds, which is the microhabitat of $R$. zhenhaiensis, whereas $B$. gargarizans tadpoles inhabit the button of ponds (Fei et al. 2009). 2) The toad tadpole and the frog tadpole taste differently to predators (Wei et al. 2013), which results in different the levels of tail damage between the two species. Many toad tadpoles are toxic and unpalatable to most aquatic predators, which decreases their chances of being predated and consequently losing their tails (LAURILA 1998, Álvarez \& Nicieza 2009, Nelson et al. 2011a, b). On the other hand, the frog tadpole lacks the ability to produce toxins, which results in more attacks from a greater variety of predators (Werner \& McPeer 1994, LaURILA et al. 2002, Wilson et al. 2005). 3) B. gargarizans and R. zhenhaiensis tadpoles differ in coloration. The former species has more intense colors (Fer et al. 2009). Mimetic coloration could help tadpoles with relatively lower swimming speed to hide in natural surroundings, and hence make them difficult to find by aquatic predators that have acute visual senses (Blair \& Wassersug 2000, VAN BUSKIRK et al. 2003, 2004, DAYTON et al. 2005). 4) After accounting for $8.2 \mathrm{~mm}$ mean body length, the mean tail length of $R$. zhenhaiensis tadpoles (16.5 mm) was greater than of B. gargarizans tadpoles $(12.2 \mathrm{~mm})$ (Table I). An enlarged tail may increase the interest of aquatic predators, resulting in a higher frequency of tail damage in tadpoles with larger tails (SMITH \& VAN BusKIRK 1995, McCollum \& Leimberger 1997, Blair \& Wassersug 2000, Van Buskirk et al. 2004). 5) The body and tail (hereafter body size) of B. gargarizans tadpoles were smaller than of $R$. zhenhaiensis tadpoles (Table I). The size of the body plays an important role in allowing tadpoles to successfully escape from aquatic predators. Tadpoles with smaller bodies can be fully devoured at once (Travis et al. 1985, FormanowiczJR 1986, CALDWELl 1994), whereas larger tadpoles are only pecked by certain small aquatic predators, resulting in increased frequency of tail damage (VAN Buskirk et al. 2004).

The results of the present study indicate that moderate tail loss decreases the swimming performance of both $B$. gargarizans and $R$. zhenhaiensis tadpoles, and more so in the former than in the latter. Additionally, when tail loss is severe, the survival rate of B. gargarizans tadpoles decreases. We predict that different strategies, such as behavior (e.g. burst speed) or chemical defense (e.g. toxic release) improve individual fitness in the face of predator pressure when the amount of tail loss of $B$. gargarizans and $R$. zhenhaiensis tadpoles is similar. 

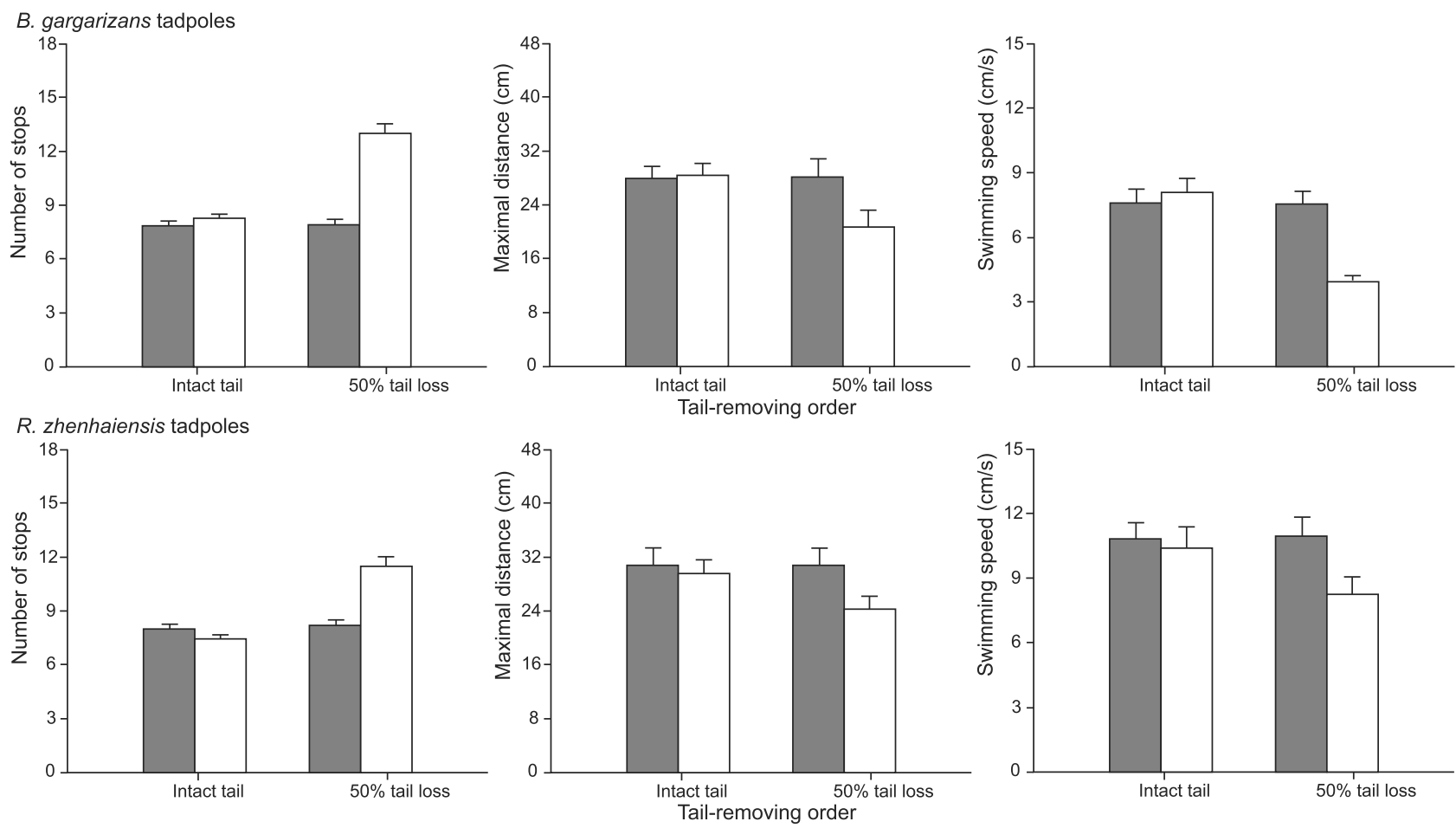

Figure 3. Mean values (+SE) for swimming performance (number of stops, maximal distance and swimming speed) in the two species before and after $50 \%$ tail loss. Black bars: $\mathrm{C}$ tadpoles; open bars: $\mathrm{E}$ tadpoles.

Table II. Results of repeated-measured ANOVA for swimming performance of two species after 50\% tail loss, with species and animal category (E vs. C tadpoles) as between-subject factors and tail-removing order as within-subject factor.

\begin{tabular}{|c|c|c|c|}
\hline & \multicolumn{3}{|c|}{ Swimming performance } \\
\hline & Number of stops & Maximal distance & Swimming speed \\
\hline Species (S) & $\mathrm{F}_{1,75}=2.12, \mathrm{p}=0.150$ & $F_{1,75}=2.13, p=0.149$ & $\mathrm{~F}_{1,75}=32.34, \mathrm{p}<0.0001 ; \mathrm{BG}<\mathrm{RZ}$ \\
\hline E vs. C tadpoles (EvC) & $F_{1,75}=44.78, p<0.0001 ; E>C$ & $\mathrm{~F}_{1,75}=4.01, \mathrm{p}<0.05 ; \mathrm{E}<\mathrm{C}$ & $\mathrm{F}_{1,75}=6.61, \mathrm{p}<0.02 ; \mathrm{E}<\mathrm{C}$ \\
\hline Tail-removing order (TRO) & $\mathrm{F}_{1,75}=107.10, \mathrm{p}<0.0001 ; \mathrm{E} 0<\mathrm{E} 1$ & $\mathrm{~F}_{1,75}=4.23, \mathrm{p}<0.05 ; \mathrm{E} 0>\mathrm{E} 1$ & $\mathrm{~F}_{1,75}=11.31, \mathrm{p}<0.002 ; \mathrm{E} 0>\mathrm{E} 1$ \\
\hline $\mathrm{S} \times \mathrm{EvC}$ & $\mathrm{F}_{1,75}=4.01, \mathrm{p}=0.049$ & $F_{1,75}=0.01, p=0.921$ & $\mathrm{~F}_{1,75}=0.01, \mathrm{p}=0.990$ \\
\hline$S \times$ TRO & $F_{1,75}=0.25, p=0.620$ & $F_{1,75}=0.13, p=0.718$ & $F_{1,75}=1.40, p=0.240$ \\
\hline $\mathrm{EvC} \times \mathrm{TRO}$ & $F_{1,75}=95.58, p<0.0001$ & $F_{1,75}=4.43, p=0.039$ & $F_{1,75}=11.76, p<0.001$ \\
\hline $\mathrm{S} \times \mathrm{TRO} \times \mathrm{EvC}$ & $F_{1,75}=0.71, p=0.403$ & $F_{1,75}=0.20, p=0.659$ & $F_{1,75}=0.94, p=0.334$ \\
\hline
\end{tabular}

BG: B. gargarizans; RZ: R. zhenhaiensis. E: E tadpoles, C: C tadpoles, E0: E tadpoles initially having intact tails; E1: E tadpoles after $50 \%$ tail loss.

\section{ACKNOWLEDGMENTS}

We thank Frank Feng, Xiao-Li Fan, Xiao-Hao Ma, Li Wei for their help during this research, and Xiang Ji for his constructive comments on early drafts of this manuscript. This project was supported by grants from National Science Foundation of China (Project 30970435 and 31270443 ), Open Research Fund program of Laboratory of Lishui University (2014-26-10) and Scientific Research Foundation of Ph.D. in Lishui University (QD1301).

\section{LITERATURE CITED}

Álvarez, D. \& A.G. Nicieza. 2009. Differential success of prey escaping predators: tadpole vulnerability or predator selection. Copeia 2009: 453-457. doi: 10.1643/CE-08-105.

ArendT, J. 2010. Morphological correlates of sprint swimming speed in five species of spadefoot toad tadpoles: comparison of morphometric methods. Journal of Morphology 271: 1044-1052. doi: 10.1002/jmor.10851.

Blair, J. \& R.J. WASSERSUG. 2000. Variation in the pattern of predator- 
induced damage to tadpole tails. Copeia 2000: 390-401. doi: 10.1643/0045-8511(2000)000[0390:VITPOP]2.0.CO;2.

Caldwell, J.P. 1982. Disruptive selection: a tail color polymorphism in Acris tadpoles in response to differential predation. Canadian Journal of Zoology 60: 2818-2827. doi: 10.1139/z82-361.

Caldwell, J.P. 1994. Natural history and survival of eggs and early larval stages of Agalychnis calcarifer (Anura: Hylidae). Herpetological Natural History 2: 57-66.

Caldwell, J.P.; J.H. Thorp \& T.O. Jervey. 1980. Predator-prey relationships among larval dragonflies, salamanders, and frogs. Oecologia 46: 285-289. doi: 10.1007/BF00346253.

Dayton, G.H.; D. Saenz; K.A. Baum; R.B. Langerhans \& T.J. DeWitt. 2005. Body shape, burst speed and escape behavior of larval anurans. Oikos 111: 582-591. doi: 10.1111/j.16000706.2005.14340.x.

Doherty, P.A.; R.J. Wassersug \& J.M. Lee. 1998. Mechanical properties of the tadpole tail fin. Journal of Experimental Biology 201: 2691-2699.

Fer, L.; S.Q. Hu; C.Y. Ye \& Y.Z. Huang. 2009. Fauna Sinica. Amphibia. Beijing, Science Press, vol. 2, p. 529-537, p. 995-1000.

Figiel, C.R. \& R.D. Semlitsch. 1991. Effects of nonlethal injury and habitat complexity on predation in tadpole populations. Canadian Journal of Zoology 69: 830-834. doi: 10.1139/ z91-125.

FormanowiczjR, D.R. 1986. Anuran tadpole/aquatic insect predator-prey interactions: tadpole size and predator capture success. Herpetologica 42: 367-373. doi: 10.2307/ 3892315

GosNER, K.L. 1960. A simplified table for staging anuran embryos and larvae with notes on identification. Herpetologica 16: 183-190. doi: 10.2307/3890061.

Hoff, K.V.S. \& R.J. WASSERSUg. 2000. Tadpole locomotion: axial movement and tail functions in a largely vertebraeless vertebrate. American Zoologist 40: 62-76. doi: 10.1093/icb/40.1.62.

Johnson, J.B.; D.B. Burt \& T.J. DeWitt. 2008. Form, function, and fitness: pathways to survival. Evolution 62: 1243-1251. doi: 10.1111/j.1558-5646.2008.00343.x.

Kishida, O.; G.C. Trussell; A. Mougi \& K. Nishimura. 2010. Evolutionary ecology of inducible morphological plasticity in predator-prey interaction: toward the practical links with population ecology. Population Ecology 52: 37-46. doi: 10.1007/s10144-009-0182-0.

LAURILA, A. 1998. Breeding habitat selection and larval performance of two anurans in freshwater rock-pools. Ecography 21: 484494. doi: 10.1111/j.1600-0587.1998.tb00440.x.

Laurila, A.; S. Pakkasmaa; P.A. Crochet \& J. Merila. 2002. Predatorinduced plasticity in early life history and morphology in two anuran amphibians. Oecologia 132: 524-530. doi: 10.1007/s00442-002-0984-7.

Laurila, A.; B. Lindgren \& A.T. Laugen. 2008. Antipredator defenses along a latitudinal gradient in Rana temporaria. Ecology 89: 1399-1413. doi: 10.1890/07-1521.1.
Lu, H.L.; J.F. GAO; X.H. MA; Z.H. Lin \& X. Ji. 2012. Tail loss affects fecundity but not offspring traits in the Chinese skink Eumeces chinensis. Current Zoology 58: 228-235.

Luquet, E.; J.P. Léna; P. David; P. Joly; T. Lengagne; N. Perrin \& S. Plenet. 2011. Consequences of genetic erosion on fitness and phenotypic plasticity in European tree frog populations (Hyla arborea). Journal of Evolutionary Biology 24: 99110. doi: 10.1111/j.1420-9101.2010.02138.x.

Maginnis, T.L. 2006. The costs of autotomy and regeneration in animals: a review and framework for future research. Behavioral Ecology 17: 857-872. doi: 10.1093/beheco/ arl010.

Marvin, V.A. 2011. Effect of body size on tail regeneration and recovery of swimming performance after caudal autotomy in a plethodontid salamander. Amphibia-Reptilia 32: 485492. doi: 10.1163/156853811X601645.

Marvin, G.A. 2013. Critical Tail autotomy for reduction of maximal swimming performance in a plethodontid salamander (Desmognathus quadramaculatus). Journal of Herpetology 47: 174-178. doi: 10.1670/12-011R.

Mccollum, S.A. \& J.D. Leimberger. 1997. Predator-induced morphological changes in an amphibian: predation by dragonflies affects tadpole shape and color. Oecologia 109: 615-621. doi: 10.1007/s004420050124.

Mccollum, S.A. \& J. Van Buskirk. 1996. Costs and benefits of a predator-induced polyphenism in the gray treefrog Hyla chrysoscelis. Evolution 50: 583-593. doi: 10.2307/2410833.

Miner, B.G.; S.E. Sultan; S.G. Morgan; D.K. Padilla \& R.A. Relyea. 2005. Ecological consequences of phenotypic plasticity. Trends in Ecology and Evolution 20: 685-692. doi:10.1016/ j.tree.2005.08.002.

Morin, P.J. 1985. Predation intensity, injury frequency, and prey survival in an amphibian predator-prey interaction. Copeia 1985: 638-644. doi: 10.2307/1444755.

Nelson, D.W.M.; M.R. Crossland \& R. Shine. 2011a. Behavioural responses of native predators to an invasive toxic prey species. Austral Ecology 36: 605-611. doi: 10.1111/j.14429993.2010.02187.x.

Nelson, D.W.M.; M.R. Crossland \& R. Shine. 2011b. Foraging responses of predators to novel toxic prey: effects of predator learning and relative prey abundance. Oikos 120: 152-158. doi: 10.1111/j.1600-0706.2010.18736.x.

SKELLY, D.K. 1997. Tadpole communities: pond permanence and predation are powerful forces shaping the structure of tadpole communities. American Scientist 85: 36-45. doi: $10.2307 / 27856689$.

Smith, D.C. \& J. VAn Buskirk. 1995. Phenotypic design, plasticity, and ecological performance in two tadpole species. American Naturalist 145: 211-233. doi: 10.2307/2463124.

Teplitsky, C.; S. Plenet \& J.P. Lena. 2005. Escape behaviour and ultimate causes of specific induced defenses in an anuran tadpole. Journal of Evolutionary Biology 18: 180-190. doi: 10.1111/j.1420-9101.2004.00790.x. 
Travis, J.; W.H. Keen \& J. Julianna. 1985. The role of relative body size in a predator-prey relationship between dragonfly naiads and larval anurans. Oikos 45: 59-65. doi: 10.2307/ 3565222.

VAN BusKiRK, J. \& S.A. Mccollum. 2000a. Functional mechanisms of an inducible defence in tadpoles: morphology and behaviour influence mortality risk from predation. Journal of Evolutionary Biology 13: 336-347. doi: 10.1046/j.14209101.2000.00173.x.

VAN BuskiRK, J. \& S.A. Mccollum. 2000b. Influence of tail shape on tadpole swimming performance. Journal of Experimental Biology 203: 2149-2158. doi: 10.1046/j.1420-9101.2000.00173.x.

Van Buskirk, J.; P. Anderwald; S. Lupold; L. Reinhardt \& H. Schuler. 2003. The lure effect, tadpole tail shape and the target of dragonfly strikes. Journal of Herpetology 37: 420-424. doi: 10.1670/0022-1511(2003)037[0420:TLETTS]2.0.CO;2.

Van Buskirk, J.; J. Aschwanden; I. Buckelmuller; S. Reolon; S. RutTiman \& S.F. Fox. 2004. Bold tail coloration protects tadpoles from dragonfly strikes. Copeia 2004: 599-602. doi: 10.1643/CE-03-283R.

Wassersug, R.J. \& K. Hoff. 1985. The kinematics of swimming in anuran larvae. Journal of Experimental Biology 119: 1-30.

Wei, L.; Z.H. Lin; R.Y. Zhao \& S.T. Chen. 2013. Prey selection by tiger frog larvae (Hoplobatrachus chinensis) of two sympatric anuran species' tadpoles. Zoological Research 34: 209-213. doi: 10.11813/j.issn.0254-5853.2013.3.0209

Werner, E.E. \& M.A. МсPEeK. 1994. Direct and indirect effects of predators on two anuran species along an environmental gradient. Ecology 75: 1368-1382. doi: 10.2307/1937461.

Wilbur, H.M. \& J.P. Collins. 1973. Ecological aspects of amphibian metamorphosis: nonnormal distributions of competitive ability reflect selection for facultative metamorphosis. Science 182: 1305-1314. doi: 10.1126/ science.182.4119.1305.

Wilson, R.S.; P.G. KRAFT \& R. VAn Damme. 2005. Predator-specific changes in the morphology and swimming performance of larval Rana lessonae. Functional Ecology 19: 238-244. doi: 10.1111/j.1365-2435.2005.00958.x.

Zottoli, S.J.; D.T. Walfish; D.A. Westbrooks \& D.C. Sмith. 2001. Small tadpoles do not initiate a startle response before being struck by the labium of dragonfly larvae. Society for Neuroscience Abstracts 27: 1984.

Submitted: 31.VIII.2013; Accepted: 12.III.2014.

Editorial responsibility: Mauricio O. Moura

ZOOLOGIA 31 (4): 316-322, August, 2014 